\title{
Fabrication and Characterization of Jute Fiber Reinforced Low Density Polyethylene Based Composites: Effects of Chemical Treatment
}

\author{
M. J. Miah" ${ }^{\mathrm{a}}$, M. A. Khan ${ }^{\mathrm{b} *}$, and R. A. Khan ${ }^{\mathrm{b}}$ \\ ${ }^{a}$ Chittagong University of Engineering and Technology, Chittagong-4349, Bangladesh \\ ${ }^{\mathbf{b}}$ Institute of Radiation and Polymer Technology, Bangladesh Atomic Energy Commission, P.O. \\ Box-3787, Dhaka-1000, Bangladesh
}

Received 4 January 2011, accepted in final revised form 25 March 2011

\begin{abstract}
Jute fiber reinforced low density polyethylene (LDPE) composites (10-30\% fiber, by weight) are prepared by compression molding. Tensile strength (TS), bending strength (BS) and bending elongation (BE) of the composites are increased over LDPE. Jute fiber is treated with monomer (2-hydroxyethyl methacrylate, HEMA) along with two different initiators in methanol solvent. Jute fibers are soaked with 10\% HEMA+2\% Irgacure-184 (F1-Formulation) and 3\% HEMA+2\% benzol peroxide (F2-Formulation) and dried at $80^{\circ} \mathrm{C}$ for 2 hours then composites are fabricated by compression molding. It is found that due to chemical treatment of the jute fibers, a significant improvement of the mechanical properties of the composites are happened (56\% TS, 30\% BS and 35\% BE) compared to the LDPE. $3 \%$ HEMA+2\% benzol peroxide treated jute composites found better mechanical properties compared to 10\%HEMA+2\% Irgacure-184 treated jute composites. Dielectric constant and loss tangent of the composites are increased with increasing temperature up to a transition temperature and then decreased, finally reached to plateau. Scanning Electron Microscopic (SEM) analysis of the fracture side of the composites are carried out and supported better fiber-matrix adhesion due to the chemical treatment.
\end{abstract}

Keywords: Jute fiber; Polyethylene; Composite; Tensile strength; Bending strength; Dielectric constant; Loss tangent.

(c) 2011 JSR Publications. ISSN: 2070-0237 (Print); 2070-0245 (Online). All rights reserved.

doi:10.3329/jsr.v3i2.6763

J. Sci. Res. 3 (2), 249-259 (2011)

\section{Introduction}

Natural polymer like jute, kenaf, pineapple, flax, wood etc are biodegradable and easily decomposable in the environment. To keep the environment free from pollution, the use of biodegradable and environmental friendly polymer is important and hence scientists all over the world are becoming interested in natural polymer. Nowadays, natural polymer jute is loosing its demand in the local and foreign market because jute fibers do not possess necessary mechanical properties desirable for engineering plastic. A notable

\footnotetext{
*Corresponding author: makhan.inst@gmail.com
} 
disadvantage of jute fibers is their polarity which makes it unsuited with hydrophobic matrix. This incompatibility results in poor interfacial bonding between fibers and matrix. The survival of the use of jute depends on the demand of jute as preferred material. On the other hand, synthetic polymer such as polystyrene, polyethylene, polypropylene, polyvinyl chloride etc. have higher mechanical properties, sustainability and durability compared to the natural polymer. But they are not biodegradable and they cause pollution of the environment. With this aim in mind many researchers developed different composites by the combination of natural and synthetic polymers and some of them have already been used as industrial products. Among synthetic polymers, polyethylene possesses outstanding properties like low density, low cost, good flex life, good surface hardness, scratch resistance and excellent electrical insulating properties [1]. Jute fiber is predominantly polar due to the presence of various polar groups on its backbone [2]. On the contrary, polyethylene is nonpolar [3]. So, for better interaction between the two incompatible surfaces, the presence of a compatibilizer is envisaged [4]. Jute-polyethylene composite containing benzol peroxide treated jute fabric reports remarkable increase in mechanical properties [5]. As jute is abundantly available in tropical countries, it is worthwhile to study jute-polyethylene composites with an aim to achieve comparable properties of other filled polyethylene composites. A lot of research works are going on to improve the quality of the composites more [6-13] and most of the articles reported only mechanical properties. But, in this investigation both mechanical and electrical properties specially dielectric constant and loss tangent of untreated and chemically treated jute fiber reinforced LDPE composites have been investigated. Moreover, here jute fibers are cured only by thermal method (dried at $80^{\circ} \mathrm{C}$ for 2 hours). To improve fiber matrix adhesion inside composites, jute fabric is treated with 10\% HEMA (2-hydroxy ethyl methacrylate) monomer $+2 \%$ Irgacure-184 (as photo-initiator) and 3\%HEMA monomer $+2 \%$ Benzol peroxide (as photo-initiator). Mechanical and electrical properties of the untreated jute composites are compared with both types of chemically treated jute based composites.

\section{Experimental}

\subsection{Materials}

Jute fiber (Hessian cloth) is collected from Bangladesh Jute Research Institute, Dhaka. Low-density polyethylene (LDPE) is purchased from Polyolefin Company Ltd. Singapore. Monomer (2-hydroxyethyl methacrylate, HEMA) is procured from Merck, Germany. Photo-initiator (Irgacure-184) is collected from Ciba-Geigy, Switzerland. Benzol peroxide (BPO) and solvent (methanol) are purchased from BDH, UK.

\subsection{Methods}

\subsubsection{Preparation of Composites}

Jute fibers are treated with monomer (2-hydroxyethyl methacrylate, HEMA) along with two different initiators in methanol solvent. Composition of the formulations (Termed as 
F1 and F2) are given in Table 1. Jute fibers are soaked (15 min) in 10\% HEMA+2\% Irgacure-184 (F1-Formulation) and 3\% HEMA+2\% benzol peroxide (F2-Formulation) and dried in the oven at $80^{\circ} \mathrm{C}$ for 2 hours then composites are fabricated by compression molding using heat press (Carver INC, USA, Model-3856). The composites are prepared by sandwiching two layers of jute between three layers of LDPE sheets. The LDPE sheets (0.5-1.0 mm thickness) are prepared by heating the polymer granules at $115^{\circ} \mathrm{C}$ for $5 \mathrm{~min}$ between two steel plates under a pressure of 3 ton. Prepared LDPE sheets are cooled to room temperature $\left(25^{\circ} \mathrm{C}\right)$, cut to desired size and kept in the plastic bag for composite fabrication. Composites are prepared at $135^{\circ} \mathrm{C}$ and 5 ton pressure using same heat press.

Table 1. Composition of formulations (\% w/w).

\begin{tabular}{ccccc}
\hline Formulations & HEMA & MeOH & \multicolumn{2}{c}{ Photoinitiator } \\
\cline { 3 - 5 } & & & Irg-184 & Benzol peroxide \\
\hline F1 & 10 & 88 & 2 & 0 \\
F2 & 3 & 95 & 0 & 2 \\
\hline
\end{tabular}

\subsubsection{Measurement of mechanical properties}

The mechanical properties such as tensile strength (TS), bending strength (BS) and bending elongation (BE) of LDPE sheets and the composites are determined by universal testing machine (INSTRON, model 1011, UK). Tensile strength measurements and three point bending tests are carried out following DIN 53455 and DIN 53452 standard methods respectively. All the results are taken as the average values of at least 10 samples.

\subsubsection{Measurement of dielectric properties}

The dielectric properties, especially the dielectric constant and the dielectric loss of both the treated and untreated composites are calculated from the measured capacitance of samples using the relation $\varepsilon=C / C_{o}$, where $C$ is the capacitance of the samples and $C_{0}$ is the capacitance of the samples in vacuum. $C_{0}$ is calculated from the knowledge of dimensions of the sample using the following relation, $C_{0}=8.85 \times 10^{-12} \times A / t$, where, $t$ is the thickness of the sample in meter. The dielectric properties are measured over the temperature range from $20^{\circ} \mathrm{C}$ to $80^{\circ} \mathrm{C}$ at frequency $10 \mathrm{kHz}$.

\subsubsection{Scanning electron microscopic (SEM) analysis}

The fracture surface of the composites is investigated by Scanning Electron Microscope (JEOL-SEM, Japan, Model 6400) at an accelerating voltage of $10 \mathrm{kV}$. SEM specimens are sputter-coated with gold. 


\section{Results and Discussions}

\subsection{Mechanical properties of jute/LDPE composites}

\subsubsection{Tensile strength (TS) of the composites}

Fibers are soaked with 10\% HEMA+2\% Irgacure-184 (F1-Formulation) and 3\% HEMA+2\% benzol peroxide (BPO) (F2-Formulation) and dried at $80^{\circ} \mathrm{C}$ for 2 hours. Using these treated fibers, low density polyethylene (LDPE) based composites are fabricated by compression molding. The fiber content in the composites varies from $10-30 \%$ by weight. Untreated jute fiber reinforced LDPE matrix composites are also fabricated using same method. Tensile strength (TS) of the matrix (LDPE), and untreated jute based composites are compared with two types of the composites. The results are presented in Fig. 1. TS of LDPE is found to be $15 \mathrm{MPa}$. It is found that TS of three types of composites (untreated, HEMA treated and BPO treated) increases with the increase of jute content up to $25 \%$ and then decreases. Untreated jute based composites performs about 37\% enhancement of TS. But $49 \%$ and $56 \%$ improvement of TS are found for 10\%HEMA+2\% Irgacure-184 treated and 3\%HEMA+2\%BPO treated jute based composites. This is clear that BPO performs better than that of Irgacure-184. BPO generates free radicals during composite fabrication and these free radicals can initiate free radical reaction which reacts with HEMA and cellulose back bone of jute fiber and thereby improves fiber matrix adhesion. The reaction between HEMA monomer and cellulose (major constituent of jute) is shown in scheme (a).

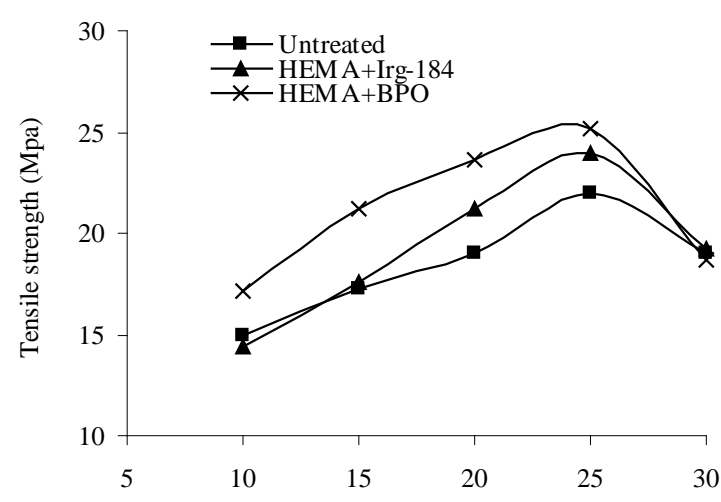

Jute content in the composites(wt\%)

Fig. 1. Effect of jute content on the tensile strength.

Basically initiators (benzol peroxide and Irgacure-184) help to start initiation reaction (formation of free radical oxygen) of monomer (HEMA) but not take part in the reaction. 
Homo-polymerization reaction can occur with the formation of poly-HEMA (scheme-b). Benzol peroxide is an oxidizing agent and it can ionize quickly than Irgacure-184. HEMA treatment of the jute fibers decreases the hydrophilic nature of the jute which attributes higher TS over the control composites [14].

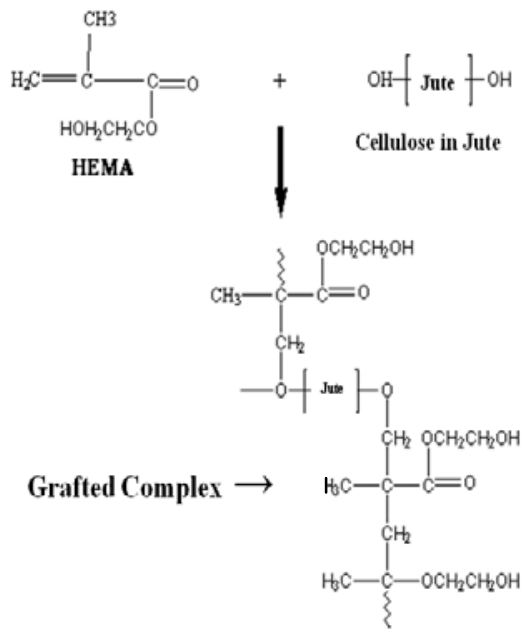

(a)

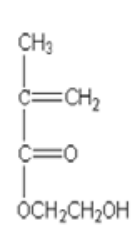

HEMA

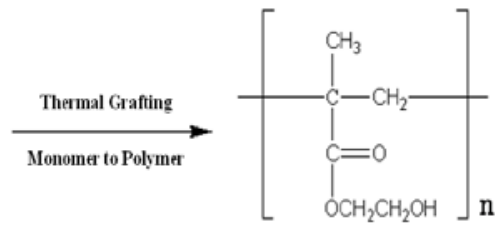

PHEMA

(b)

Scheme: Reaction between HEMA and Cellulose of jute (a) and formation of polymer (poly-HEMA) (b).

\subsubsection{Bending strength (BS) of the composites}

BS both of the treated and untreated composites has been measured as a function of jute content; the result is shown in Figure.2. BS of the composites increases with the increase of jute content like TS but reaches the maximum for $20 \%$ fiber content then decreases. High fiber content is responsible for poor fiber matrix adhesion. Similar results are reported elsewhere for jute/polyester amide composites [14].Chemical treatment of jutefiber plays an important role on its mechanical properties. HEMA and BPO treated composites have higher values of BS than that of untreated composite. Observation proves that there is a poor interaction between fiber and matrix in the untreated composites. In the chemically treated composites, interaction between fibers and matrix is strong and fibers are uniformly spread in the composites thus prevented to form a bundle. $30 \%$ improvement of BS has been found for the BPO+HEMA treated composite than the LDPE. 


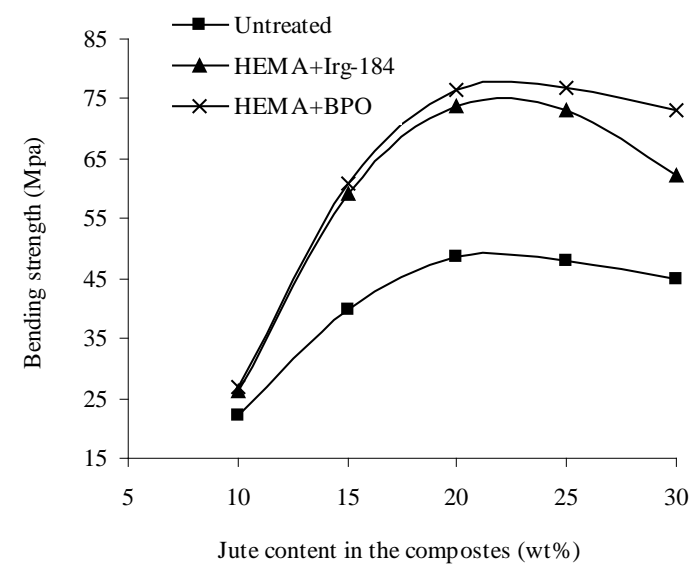

Fig. 2. Effect of jute content on the bending strength.

\subsubsection{Bending elongation (BE) of the composites}

$\mathrm{BE}$ of treated and untreated composites with respect to jute content is presented in Figure 3. BE of benzol peroxide treated jute based composite shows better result than that of untreated sample and Irgacure-184 treated sample. Maximum value of BE for untreated and BPO treated jute composites is found for $20 \%$ jute content. Whereas, for Irgacure-184 treated jute composite, the maximum value of BE is found for $25 \%$ jute content. This may be due to elasticity of jute fibers which depends simultaneously both on amounts of fiber and chemical treatment process. The significant information of this part of research is the improvement of BE for jute/LDPE composites. Hence, it can be concluded that using chemical treatment have the potentially to improve $\mathrm{BE}$ to the required range.

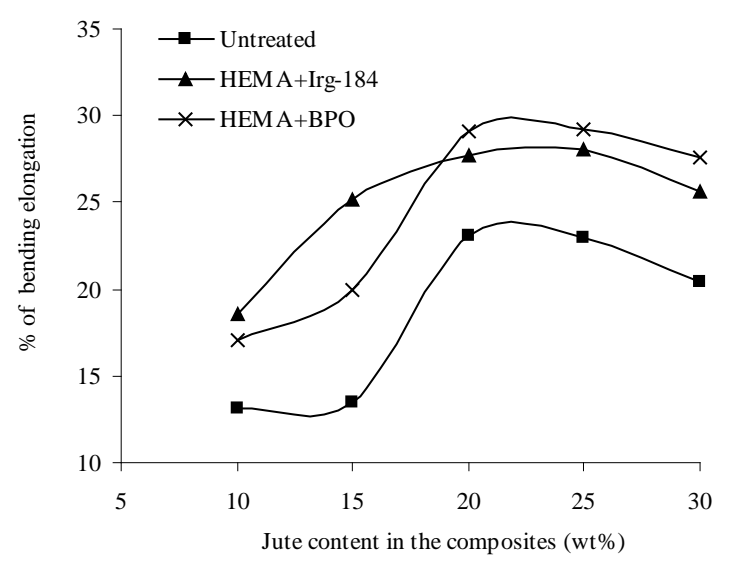

Fig. 3. Effect of jute content on the \% of bending elongation. 


\subsection{Dielectric behavior of the jute/LDPE composites}

Dielectric properties such as dielectric constant and loss tangents of both untreated and chemically treated composites were studied with the variation of jute content at a fixed frequency of $10 \mathrm{kHz}$. The variation of dielectric constant with temperature for the composites containing 10, 20 and 30\% jute fiber is given in Fig. 4. On the other hand, dependence of loss tangent with temperature for the composites (10, 20 and 30\% fiber content) is presented in Fig. 5.

Fig. 4 shows the variation of dielectric constant with temperature for untreated, 10\%HEMA+2\%Irgacure-184 treated and 3\%HEMA+2\%BPO treated jute based composites.
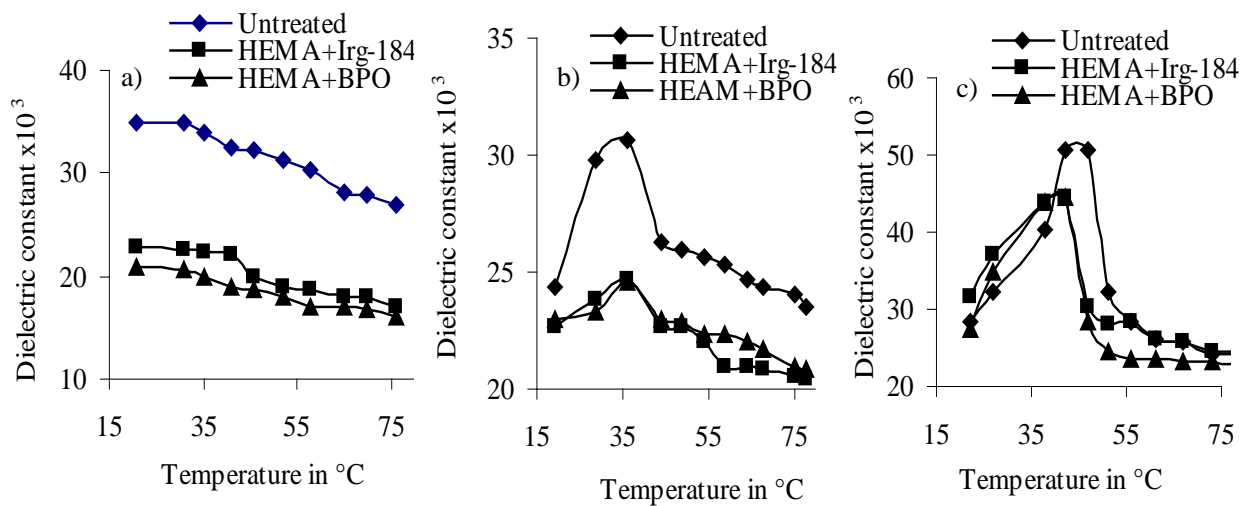

Fig. 4. Dependence of dielectric constant on temperature for a) $10 \%$ jute based composites b) $20 \%$ jute based composites and c) $30 \%$ jute based composites.

All the curves obtained for the composites containing 10\% jute fabric (Fig. 4a) show the same pattern. Dielectric constant of untreated and treated composites decreases irregularly with some fluctuation with temperature. Dielectric constant for untreated composite is found higher than those of the treated composites. 10\%HEMA+2\%Irgacure184 treated jute composite shows higher value of dielectric constant than the BPO treated jute/LDPE composite. For the untreated composite containing 20\% jute fabric (Fig. 4b), it is found that dielectric constant initially increases very sharply with increasing temperature and the maximum value reaches at $36^{\circ} \mathrm{C}$. Above this temperature, the dielectric constant drops sharply up to $44^{\circ} \mathrm{C}$ and then it decreases slowly with increasing temperature. Above $75^{\circ} \mathrm{C}$ the dielectric constant remains constant with increasing temperature. Composites treated with 10\%HEMA+2\%Irgacure-184 and $3 \%$ HEMA+2\%BPO show the same pattern as the untreated one. Dependence of dielectric constant with temperature for untreated and treated composites containing 30\% jute fabrics shows the same nature (Fig. 4c) as the $20 \%$ jute fabric composites. Initially the 
dielectric constant for untreated composite increases very sharply with increasing temperature and the maximum value reaches at $47^{\circ} \mathrm{C}$. Above this temperature, dielectric constants decrease very sharply up to $56^{\circ} \mathrm{C}$ and then decrease slowly up to $70^{\circ} \mathrm{C}$. For further increase in temperature, dielectric constant remains constant. Dielectric constant for treated composites has maximum value at $42^{\circ} \mathrm{C}$. Loss tangent both of treated and untreated composites containing 10\% jute fabric (Fig. 5a) initially increase and then decrease with increasing temperature. After that the loss tangent for both untreated and treated composites remains constant. For the composites containing 20\% jute fabric (Fig. $5 b)$, the dielectric loss tangent increases rapidly with increasing temperature up to $36^{\circ} \mathrm{C}$ for both untreated and treated. Above $36^{\circ} \mathrm{C}$, the loss tangent decreases sharply with increasing temperature which is in conformity with the dielectric behavior i.e. demonstrated the presence of phase transition. For the composites containing 30\% jute fabric the transition is found at around $40 \sim 45^{\circ} \mathrm{C}$ (Fig. $5 \mathrm{c}$ ). Untreated composite shows the transition at $44^{\circ} \mathrm{C}$ and treated composites (both types) show the transition at $41^{\circ} \mathrm{C}$.
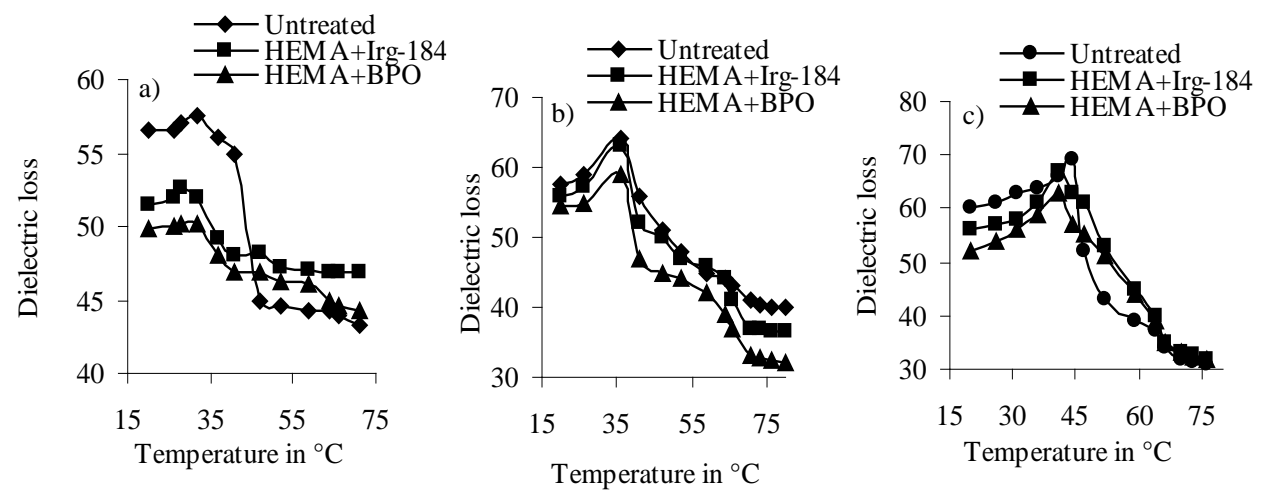

Fig. 5. Dependence of dielectric loss on temperature for a) $10 \%$ jute based composites b) $20 \%$ jute based composites and c) $30 \%$ jute based composites.

Above investigation clearly reveals that dielectric constant is lower for treated composites over the untreated one. This is because of the free radials generation during composites fabrication at high temperature. It is also apparent that BPO treated jute composites show low dielectric constant compared to Irgacure-184 treated jute based composites which indicates higher free radical formation of BPO during the process of composites preparation. No transition is found for the composites containing $10 \%$ jute fabric (both treated and untreated). Composites containing 20\% and 30\% jute fabric (both treated and untreated) undergo a definite phase transition. Here it is concluded that when jute content is increased, it undergoes a transition. It is reported that jute fiber is a ferroelectric material [15]. The transition observed in the present study may be associated with ferro-paraelectric transition. For definite conclusion about the nature of transition hysteretic loop study is needed. The synthetic polymer LDPE has excellent chemical 
inertness and electrical insulating properties. The effect of LDPE is dominated in the composites containing less than $20 \%$ of jute and hence there is no clear evidence of phase transition in those composites. The transition temperature is same for both the treated and untreated composites containing $20 \%$ jute fabrics. Whereas, the transition temperature in untreated composite is higher than that of the treated composites of $30 \%$ jute fabric. During fabrication of the composites, initiator produces free radicals in the treated composites and they contribute to reduce the electrical insulating properties. All the measurements (except 10\% jute based composites) show that dielectric values increase up to a transition temperature and above the transition temperature it decrease and with further increase of temperature it reduce to a constant value. Jute is a hydrogen-bonded material [16]. The hydrogen bonds break to form dipoles with increasing temperature. These dipoles tend to align with the electric field and thus increase the dielectric constant. At the transition temperature, the alignment of dipoles towards the field is the highest which gives rise to maximum dielectric value. Above the transition temperature, the dipoles tend to be random. As the randomness increases with increasing temperature, the dielectric values decrease and eventually becomes constant.

\subsection{Scanning electron microscopic (SEM) analysis}

Scanning electron microscopic (SEM) investigation of the fracture surface of the jute composites is performed to study interfacial properties between jute fiber and LDPE matrix. SEM images of fracture surface of untreated (a), 10\%HEMA+2\%Irgacure-184 treated (b) and 3\% HEMA+2\%BPO treated (c) jute/LDPE composite are presented in Fig. 6.
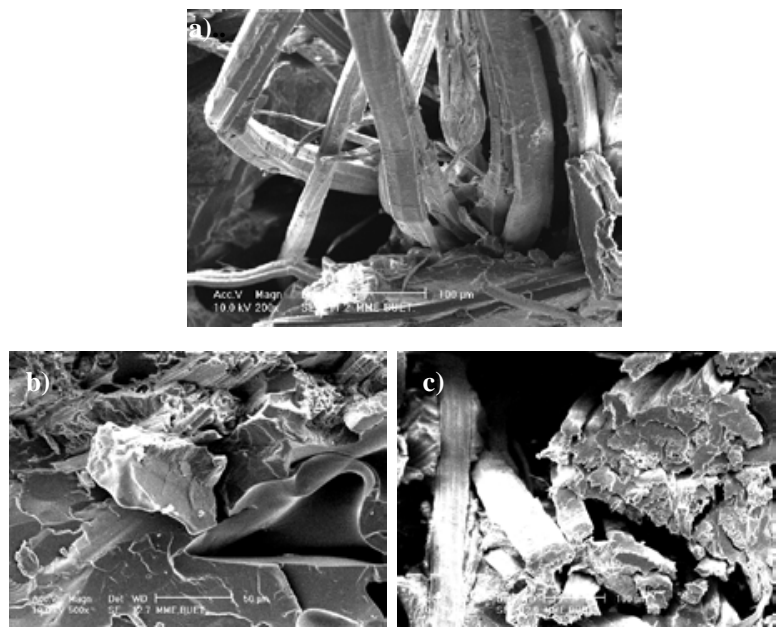

Fig. 6. SEM images of fracture surface of a) untreated jute fiber/PE composite b) $10 \%$ HEMA + 2\% Irgacure-184 treated Jute/PE composite and c) 3\%HEMA + 2\% BPO treated Jute/PE composite. 
The figure clearly indicates that there is considerable difference in the fiber-matrix interaction between the treated and untreated jute composites. Fiber pull-out phenomena is observed for all cases but for untreated jute composite fiber pull-out is observed in bundle form where as in chemically treated composites agglomeration of the fibers into bundle form is relatively prevented. Between the treated samples, 3\%HEMA+2\%BPO treated jute/LDPE composite (Fig. 6c) shows significant change of morphology and this is effective for better mechanical bonding between fiber and polymer matrix.

\section{Conclusions}

Natural fiber, jute is treated with 10\% HEMA+2\% Irgacure-184 and 3\%HEMA+2\%BPO then dried at $80^{\circ} \mathrm{C}$ for 2 hours. Low density polyethylene (LDPE) based composites are fabricated by using untreated and treated jute fibers by compression molding. Tensile strength (TS), bending strength (BS) and bending elongation (BE) of the composites are found higher than the matrix polymer LDPE. It can be concluded that jute reinforced properly with LDPE. Due to chemical treatment of the jute fibers, a significant improvement of the mechanical properties of the composites is found over untreated jute/LDPE composites. 3\%HEMA+2\% BPO treated jute composites show better mechanical properties compared to 10\% HEMA+2\% Irgacure-184 treated jute composites. Dielectric constant and loss tangent of the composites are increased with increasing temperature up to a transition temperature and then decreased, finally reached to plateau. Scanning Electron Microscopic (SEM) analysis supports better fiber-matrix adhesion due to the chemical treatment. The importance of this investigation is to improve the mechanical properties of the jute based composites by HEMA treatment of the jute fibers. Two types of initiators are also found potential for the improvement of strength but BPO performs better results. In conclusion, chemical treatment of jute has the capability to improve the fiber matrix which is attributed to better mechanical properties.

\section{References}

1. J. A. Brydson, Plastic Materials, $3^{\text {rd }}$ edition (Newnes Butterworths, London, 1975).

2. S. M. Lee (ed.), International Encyclopedia of Composites, Vol. 4 (VCH, New York, 1990).

3. H. F. Mark, N. G. Gaylord, and N. M. Bikales (eds.), Propylene Polymers, Encyclopedia of Polymer Science and Technology, Vol. 11 (Interscience, Wiley, New York, 1969).

4. J. Stepek and H. Daoust, Additives for Plastics, Vol. 5, Chapt. 4 (Springer-Verlag, New York, 1983).

5. M. J. Miah, F. Ahmed, A. Hossain, A. H. Khan, and M. A. Khan, Polym. Plast. Tech. \& Eng. 44, 1443 (2005).

6. U. Z. Haydar, A. H. Khan, A. Hossain, M. A. Khan, and R. A Khan, Polym. Plast. Tech. \& Eng. 48,760 (2009).

7. M. A. Khan, R. A. Khan, Haydaruzzaman, G. Sushanta, M. N. A. Siddiky, and M. Saha, Polym. Plast. Tech. \& Eng. 48, 542 (2009).

8. M. Ramakrishna, V. Kumar, and N. S. Yuvraj, J. Reinf. Plast. \& Composites 28, 1169 (2009). 
9. H. S. Yang, H. J. Kim, B. J. Lee and T. S. Hwang, Comp. Struct. 72, 429 (2006). doi:10.1016/j.compstruct.2005.01.013

10. F. Vilaseca, J.A. Mendez, A. Pelach, M. Llop, N. Canigueral, J. Girones, Process Biochemistry 42, 329 (2007). doi:10.1016/j.procbio.2006.09.004

11. M. S. Jamil, I. Ahmed, and I. Abdullah, J. Poly. Res. 13, 315(2006).

12. C. Scarponi and C. S. Pizzinelli, Int. J. Mat. \& Prod. Tech. 36, 278 (2009). doi:10.1504/IJMPT.2009.027837

13. X. Li, S. Panigrahi and L. G. Tabil, Am. Soc. Agr. \& Bio. Eng. 25 (4), 525 (2009).

14. A. K. Mohanty, A. M. Khan, and G. Hinrichsen, J. Comp. Sci. \& Tech. 60, 1115 (2000).

15. L. R. Das, M.Sc.Thesis, Dept. of Physics, Jahangirnagar University, Dhaka, Bangladesh (2000).

16. E. Frollini, A. L. Leao, and L. H. C. Mattoso (eds.), (Instrumentacao Agropecuaria: San Carlos, Brazil, 2000) pp.115-134. 